\title{
Rethinking Theories of First Language Acquisition and Seeking Implications for Second Language Education: Impoverished Input vs. Degenerate UG
}

\author{
Mohammad Amin Mozaheb ${ }^{1}$, Amin Naeimi² \\ ${ }^{1}$ Imam Sadiq (A) University, Tehran, Iran \\ ${ }^{2}$ Islamic Azad University, Yazd Branch, Yazd, Iran \\ Email: mozaheb.ma@gmail.com
}

Received 2 April 2016; accepted 16 April 2016; published 19 April 2016

Copyright (C) 2016 by authors and OALib.

This work is licensed under the Creative Commons Attribution International License (CC BY). http://creativecommons.org/licenses/by/4.0/

(c) () Op Open Access

\begin{abstract}
Mainly inspired by Chomsky, Forder and Pinker, nativists put an end to the scientific predominance of empiricists by underpinning the existence of an innate predisposition as the source of linguistic competence. Nativists persuasively emphasized the limitations of the primary linguistic data available to the child as impoverished. Prone to challenge, yet, they were as social interactionists whom revealed important issues missed in nativists' arguments as how, and whether, Language Acquisition Device (LAD) suffices in imbuing us in the course of language acquisition. Although interactionists have also been criticized as not precisely specifying the role of external and internal factors in language development, their contributions worth the effort of a careful scrutiny which certainly proves useful in yielding insights for second language teaching and learning. As such, the present study is aimed to recast the heated issue of first language acquisition as taken hold by various, sometimes sharp, pendulum swings in linguistics, psychology and education. The study, specifically, evaluates influential studies on the role of the triggering input and the genetically determined learning capacity.
\end{abstract}

\section{Keywords}

UG, Input, First Language Acquisition, Behaviorism, Cognitivism, Nativism, Humanistic Approach, Interactionism, Connectionism

Subject Areas: Education, Linguistics

How to cite this paper: Mozaheb, M.A. and Naeimi, A. (2016) Rethinking Theories of First Language Acquisition and Seeking Implications for Second Language Education: Impoverished Input vs. Degenerate UG. Open Access Library Journal, 3: e2296. http://dx.doi.org/10.4236/oalib.1102296 


\section{Introduction}

Seduced by theories postulated by Chomsky and other key figures in a field defined as Linguistics concerning First Language Acquisition, we started reading the recent articles related to the mentioned issue. What we discovered was interesting and we decided to write a research article about the findings. At the very beginning of our study, we posed a number of questions to widen our views which appear below:

1. What does each theory talk about/consider as important? 2. What do we mean and what do we know about mental processes/states? 3. Does Behaviorism really exclude the role of mind? Or is it given a secondary/subsidiary role? Regarding the scientific advances at that time, can Behaviorism be forgiven or justified? 4. What are the manifestations of each theory in language teaching and learning? 5 . How did the academic practitioners employ each theory? 6 . What are the applications and implications of their assertions? 7. How does each theory define learning? 8. To what degree are the theories opposed to each other? 9. What are the merits/drawbacks/caveats of each theory?

After raising the questions, we started collecting and mining data in order to find an answer for each of them; for instance, for the first question we come up with this answer: Behaviorism-a theory that its perspective can be defined as a change of behavior as a result of experience which can be measured-purports to consider patterns of behavior. The main issue perused in Nativism is the role of predisposed genetically determined, innate and learner-internal system. To put another way, its main concern is the creative aspects of human being's learning.

In the following paragraphs the authors try giving a comprehensive picture of learning theories in today's world.

Minding our data, we could summarize the Behavioristic view of psychology in the following ways.

\section{Behaviorism}

The primary focus of the theory was on observable behavior in addition to stimulus-response connections which the former happens in the nature usually and the latter often occurs when people use conditioning for animals. In other words, the main assumption is the fact that learning is a result of environmental forces and the main theorists dominating the approach are Edward Thorndike, Ivan Pavlov, John B. Watson and B.F. Skinner. In this theory, a number of principles were mentioned such as time/place pairings, biological basis of behavior, consequences or the definition claiming that learning is the result of the application of consequences; that is, learners begin to connect certain responses with certain stimuli while learning and the final principle was modeling. The main examples mentioned in the theory were positive reinforcement and negative reinforcement (see, for instance, Skinner \& Ferster, [1]). Even though the theorists did their best to use this theory as the main one in language development, a number of criticisms such as simplistic explanation, overlooking learner contribution and untestability refuted this theory. Additionally, little attention was paid to cognition and the theorists ignore un-reinforceable development and unreinforced productions, an example for the former is phonological knowledge and for the latter we can say that the theory does not explain the acquisition of underlying rules (Graham, [2]).

Seeking to understand the nature of First Language Acquisition, we would sit in front of massive databases covering Behaviorism, facing the evidence of the devastation wrought on behavioristic theory as a theory of language by Cognitivism which will be explained below.

\section{Cognitivism}

Following the downfall of Behaviorism in the wake of criticisms, Cognitivism emerged as a new theory which its perspective is a change in mental associations and representations brought about by experiences (Graham, [2]). The primary focus of the theory was on mental behavior, knowledge, intelligence and critical thinking which all of them led to the assumption that learning is a result of mental operations/processing. Key figures proposing ideas in Cognitivism are Benjamin Bloom, Jean Piaget and Robert M. Gagne. They set out a number of general principles such as memory is limited, changes happen over time and good thinking needs a number of standards. The scholars concerned with this theory think that there are some hierarchies regarding educational goals and objectives and also there are some stages in mental development. According to Atkinson and Shiffrin ([3], p. 90), Information Processing Model mentioned in the theory is "the study of the structure and function of mental processing within specific contexts, environments, or ecologies". Another concept which is regarded as a turning point by many scientists in Cognitivism is the emergence of Critical Thinking defined by Huitt and 
Hummel ([4], p. 24) as "how we apply our cognitive processes to evaluating arguments (propositions) and making decisions." An example of which can be thinking to a standard. Heavy data mining helped us to understand the nature of Paiget's [5] Model of Cognitive Development. According to Piaget [5], there are four stages including Sensorimotor stage (Infancy), Pre-operational Stage in which the use of symbols, memory and imagination by toddlers is important and thinking is non-logical and non-reversible, Concrete operation stage dealing with elementary and early adolescence by which intelligence is shown through logical and systematic manipulation of symbols linked to concrete objects, and Formal operational stage which is usually defined for adults in which intelligence can be shown through the logical use of symbols linked to abstract concepts.

Given the importance of Cognitivism, Chomsky's Universal Grammar introduced two main issues, namely, Language Acquisition Device (LAD) and Universal Grammar which are important components of nativist theories of language acquisition (Cook \& Newson, [6]).

\section{Nativism}

According to Lightbown and Spada ([7], p. 15), "Children are born with a specific innate ability to discover for themselves the underlying rules of a language system on the basis of the samples of a natural language they are exposed to.” Additionally, when describing nature vs. nurture, Chomsky [8] states that the characteristics of complex organisms "are in general a complicated product of inborn structure, the genetically determined course of maturation, and past experience” (p. 27). Graham ([2], p. 25) further noticed that "It appears to be a fundamental fact about human beings that our behavior and behavioral capacities often surpass the limitations of our individual reinforcement histories. Our history of reinforcement often is too impoverished to determine uniquely what we do or how we do it. Much learning, therefore, seems to require pre-existing or innate representational structures or principled constraints within which learning occurs". Surveying the related literature and after heavy mining of the data, we can say that Chomsky defined nativism regarding human nature.

\section{Chomskyan Nativism}

“The child's language 'grows in the mind' as the visual system develops the capacity for binocular vision, or as the child undergoes puberty at a certain stage of maturation. Language acquisition is something that happens to a child placed in a certain environment, not something the child does.” (Chomsky, as cited in Cowie, [9], p. 153). Another important issue proposed for the first time by Chomsky was Universal Grammar which according to Lightbown and Spada ([7], p. 225), can be defined as "Innate linguistic knowledge which, it is hypothesized, consists of a set of principles common to all languages. This term is associated with Chomsky's theory of language acquisition”. Comparing Cognitivism and Behaviorism, we can outline the main issues as follows:

1. Behaviorism is commonly not recognized as an acceptable theoretical explanation for the development of complicated cognitive systems in human beings an example of them is language. 2. The nativist description of language development, as acquired not learned, is diametrically against behavioral theories which put an emphasis on behaviors. 3. It is possible that different theoretical descriptions might account for the development of different aspects of language and/or communication (Graham, [2]).

To sum up this section of our data mining, both Behaviorism and Cognitivism are defined as learning theories which have their differences. However, a common point emphasized by both of them is the facilitating role of environmental conditions in learning in addition to the role of practice with corrective feedback.

The next important issue which we want to write about it here is the Humanistic approach which will be discussed in the next section.

\section{Humanistic Approach}

The primary focus of the approach is on affect/values, self-concept/self-esteem and needs. Scientists belonging to this approach such as Carl Rogers and Abraham Maslow assume that learning is a result of affect/emotion and it is goal-oriented. They hold that the principles in this approach are individual uniqueness, self-determination and dreams as well as goals which are vital for success in learning. Simply, the question of what needs motivate us to act? is the motto of this approach in which affective or emotional system, embellishes and diminishes can modify information processed by people across the globe (Huitt, [10]). Self-esteem mentioned by the scholars in this approach is the basic faith in oneself as being positively oriented and growth-directed. To put it other way, individuals cannot progress since they do not have faith in their ability when it comes to solving problems (Huitt, 
[10]). According to Popper ([11], p. 56), "Humanistic Psychology has been criticized because its theories are impossible to falsify, and lacks predictive power and therefore is not a science."

The next approach we are going to discuss here is the interactionist approach technically called Interactionism.

\section{Interactionism}

According to Slideplayer ([12], p. 15), Interactionism can be defined as a "A theoretical position assuming that the individual is not only influenced by his/her environment, but that $\mathrm{s} /$ he also influences his/her environment. The emphasis is on the person taking an active, or constructive, part in his/her development." Page, Thomas \& Marshall ([13], p. 118) also defines the theory as "a social-psychological theory that the self is formed by interacting with others and that social life depends on the ability to imagine ourselves in other social roles".

The main principles of the theory are meaning, language and structure. In terms of the distinction between choices and determinism, scholars belonging to this way of thinking hold that actors can produce patters of interaction and social structure is the main source for guiding human behavior rather than strictly determining it. Another theory which attracted the attention of stake holders over the years is connectionism which will be discussed in the following part.

\section{Connectionism}

In this theory strong interconnectedness of the human brain is the main concern. There are some neural networks which are loosely modeled after the complicated biological processes involved in reasoning or better say cognition. Alexander, Frith and Frith ([14], p. 141), summarized the main principles of connectionism in this way:

“1. Information processing involves many simple elements called neurons. 2. Signals are transmitted between neurons using connecting links. 3. Each link has a weight that controls the strength of its signal. 4. Each neuron applies an activation function to the input that it receives from other neurons. This function determines its output."

They further add that links with positive weights are theoretically called by scholars as excitatory links and links with negative weights are known as inhibitory links.

In connectionism, neural network (NN) - a machine learning approach stimulated by the system in which the brain does a certain task related to learning-plays an important role. Knowledge regarding the learning task can be obtained through different forms of examples aka training examples during the learning process.

\section{Conclusion}

Having considered the data mining process with regards to the principles and definitions of the learning theories, we can conclude that Interactionism has not been recognized or admired in the way that it deserves. Scientists and scholars paid much more attention to Behaviorism, Cognitivism and Connectionism while they ignored Interactionism in the development of language of both First Language and Second Language Acquisition. We cannot say which theory is the best theory for describing language development. As such, the present study was aimed to reform the concept of first language acquisition. The study, specifically, evaluated leading studies on the role of the triggering input and the genetically determined learning capacity of learners. We cannot say language learning can be best described by using which theory. But, our data mining showed that by working more on Interactionism, scholars can obtain more about the First Language Acquisition, although Interactionists have also been criticized by a number of scholars as not exactly specifying the role of external and internal factors in language development.

\section{References}

[1] Skinner, B.F. and Ferster, C.B. (2015) Schedules of Reinforcement. BF Skinner Foundation.

[2] Graham, B. (2005) Introducing Theories of Language Learning. http://plato.stanford.edu/entries/behaviorism

[3] Atkinson, R.C. and Shiffrin, R.M. (1968) Human Memory: A Proposed System and Its Control Processes. The Psychology of Learning and Motivation, 2, 89-195. http://dx.doi.org/10.1016/S0079-7421(08)60422-3

[4] Huitt, W. and Hummel, J. (2003) Piaget's Theory of Cognitive Development. Educational Psychology Interactive. Valdosta State University, Valdosta. 
[5] Piaget, J. (1972) Intellectual Evolution from Adolescence to Adulthood. Human Development, 15, 1-12. http://dx.doi.org/10.1159/000271225

[6] Cook, V. and Newson, M. (2014) Chomsky’s Universal Grammar. John Wiley \& Sons, New York.

[7] Lightbown, P.M., Spada, N., Ranta, L. and Rand, J. (2006) How Languages Are Learned. Oxford University Press, Oxford.

[8] Chomsky, N. (1959) A Note on Phrase Structure Grammars. Information and Control, 2, 393-395. http://dx.doi.org/10.1016/S0019-9958(59)80017-6

[9] Cowie, F. (1999) What’s within? Nativism Reconsidered. Oxford University Press, New York.

[10] Huitt, W. (2015) Understanding Reality: The Importance of Mental Representations. Community Development through Academic Service Learning, Atlanta. http://www.cd-asl.org/papers/2015-huitt-mental-representations.pdf

[11] Popper, K.R. (1971) The Moral Responsibility of the Scientist. Security Dialogue, 2, 279-283. http://dx.doi.org/10.1177/096701067100200311

[12] Slideplayer (2015) Interactionism. http://slideplayer.com/slide/230380/

[13] Page, G.T., Thomas, J.B. and Marshall, A.R. (1977) International Dictionary of Education. Kogan, London.

[14] Alexander, S., Frith, K. and Hoy, H. (2014) Applied Clinical Informatics for Nurses. Jones \& Bartlett Publishers, Burlington. 